\title{
Venous thromboembolism prophylaxis in patients with
}

\section{traumatic brain injury: a systematic review [version 1; peer}

\section{review: 2 approved]}

\author{
Yohalakshmi Chelladurai ${ }^{1}$, Kent A Stevens², Elliott R Haut², Daniel J Brotman², \\ Ritu Sharma1, Kenneth M Shermock ${ }^{4}$, Sosena Kebede ${ }^{3}$, Sonal Singh1,3, \\ Jodi B Segal1,3 \\ 1John Hopkins University Bloomberg School of Public Health, Baltimore, MD, 21205, USA \\ 2Department of Surgery, Johns Hopkins University School of Medicine, Baltimore, MD, 21287, USA \\ ${ }^{3}$ Department of Medicine, Johns Hopkins University School of Medicine, Baltimore, MD, 21287, USA \\ ${ }^{4}$ Department of Pharmacy, Johns Hopkins University School of Medicine, Baltimore, MD, 21287, USA
}

V1 First published: 29 May 2013, 2:132

https://doi.org/10.12688/f1000research.2-132.v1

Latest published: 29 May 2013, 2:132

https://doi.org/10.12688/f1000research.2-132.v1

\section{Abstract}

Objective: There is considerable practice variation and clinical uncertainty about the choice of prophylaxis for preventing venous thromboembolism in patients with traumatic brain injury. We performed a systematic review to assess both the effectiveness and safety of pharmacologic and mechanical prophylaxis, and the optimal time to initiate pharmacologic prophylaxis in hospitalized patients with traumatic brain injury.

Data sources and study selection: MEDLINE®, EMBASE®, SCOPUS, CINAHL, International Pharmaceutical Abstracts, clinicaltrial.gov, and the Cochrane Library were searched in July 2012 to identify randomized controlled trials and observational studies reporting on the effectiveness or safety of venous thromboembolism prevention in traumatic brain injury patients.

Data extraction: Paired reviewers extracted detailed information from included articles on standardized forms and assessed the risk of bias in each article.

Data synthesis: Twelve studies ( 2 randomized controlled trials and 10 cohort studies) evaluated the effectiveness and safety of venous thromboembolism prophylaxis in patients with traumatic brain injury. Five of the included studies assessed the optimal timing of initiation of pharmacological prophylaxis. Low grade evidence supports the effectiveness of enoxaparin over control in reducing deep vein thrombosis. Low grade evidence also supports the safety of unfractionated heparin over control in reducing mortality in patients with traumatic brain injury. Evidence was insufficient for remaining comparisons and outcomes including the optimal timing of initiation of pharmacoprophylaxis.

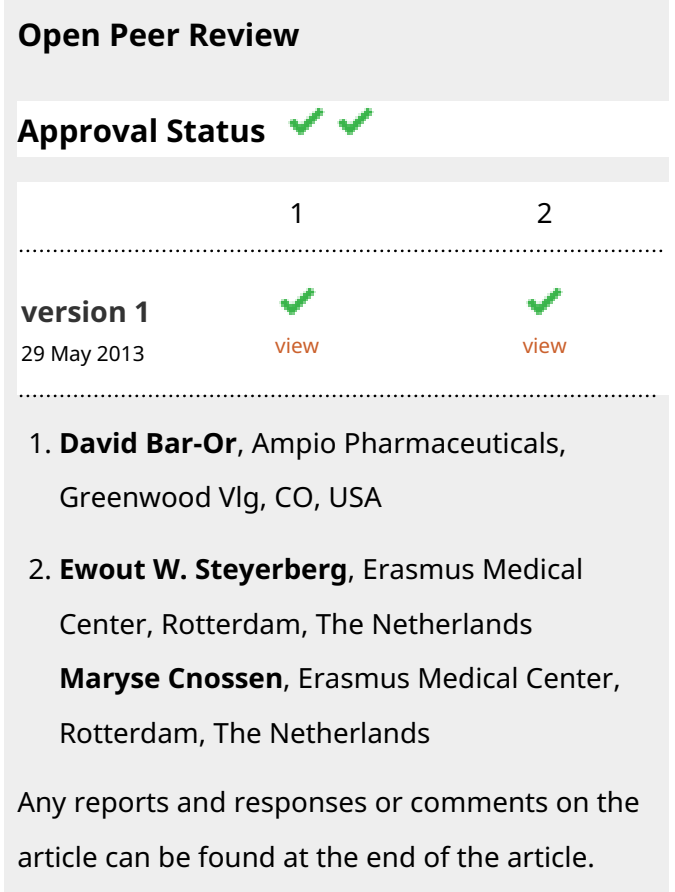


Conclusion: There is some evidence that pharmacoprophylaxis improves deep vein thromboses and mortality outcomes in patients hospitalized with traumatic brain injury. Additional studies are required to strengthen this evidence base.

Corresponding author: Kent A Stevens (ksteve14@jhmi.edu)

Competing interests: Dr Haut is the primary investigator of the Mentored Clinician Scientist Development Award K08 1K08HS017952-01 from the Agency for Healthcare Research and Quality entitled “Does Screening Variability Make DVT an Unreliable Quality Measure of Trauma Care?" Dr Haut receives royalties from Lippincott, Williams, \& Wilkins for a book he coauthored (Avoiding Common ICU Errors) and has given expert witness testimony in various medical malpractice cases. Dr. Brotman reports having been on an advisory boards for the following companies: Canyon Pharmaceuticals, Cubist Pharmaceuticals, Sanofi-Aventis Pharmaceuticals, Bristol-Myers Squibb/Sanofi Pharmaceuticals Partnership, EMCREG International, Otsuka America Pharmaceutical, Inc., Ortho-McNeil Pharmaceuticals, Johnson \& Johnson. He has consulted for Gerson Lehrman Group. The Dunn Group and Quantia Communications, LLC. He has received research support from Siemens Healthcare Diagnostics (formerly Dade Behring), Agency for Healthcare Research and Quality (AHRQ), Center for Medicare \& Medicaid Services (CMS), and Amerigroup Corporation. He has been an expert witness in various cases addressing clinical decision making and actions of Hospitalists, nurses, and other healthcare professionals. All other authors report no conflicts of interest. The authors of this article are responsible for its contents, including any clinical or treatment recommendations. No statement in this article should be construed as an official position of AHRQ or of the U.S. Department of Health and Human Services.

Grant information: This study was funded by a grant from the Agency for Healthcare Research and Quality (AHRQ), Contract number: HHSA-290-2007-10061 I. The AHRQ participated in formulating the key questions and reviewed planned methods and data analyses, as well as interim and final evidence reports. The AHRQ had no role in data collection, data management, data analysis, study selection, quality ratings, or interpretation/synthesis of the evidence.

The funders had no role in study design, data collection and analysis, decision to publish, or preparation of the manuscript.

Copyright: $@ 2013$ Chelladurai $Y$ et al. This is an open access article distributed under the terms of the Creative Commons Attribution License, which permits unrestricted use, distribution, and reproduction in any medium, provided the original work is properly cited.

How to cite this article: Chelladurai Y, Stevens KA, Haut ER et al. Venous thromboembolism prophylaxis in patients with traumatic brain injury: a systematic review [version 1; peer review: 2 approved] F1000Research 2013, 2:132 https://doi.org/10.12688/f1000research.2-132.v1

First published: 29 May 2013, 2:132 https://doi.org/10.12688/f1000research.2-132.v1 


\section{Introduction}

There is considerable practice variation and clinical uncertainty about the choice of a prophylaxis modality (pharmacologic and mechanical) and about the optimal pharmacologic agent, dose, timing of initiation, and duration for the prevention of venous thromboembolism (VTE) among patients with traumatic brain injury (TBI) ${ }^{1}$. This population is at increased risk for VTE due to a combination of factors (i.e., the brain injury itself, other injuries, intensive care unit admission, immobilization, major surgery, etc.). This increased risk should prompt routine thromboprophylaxis in patients with TBI; however, the concern over an associated elevated risk of bleeding in patients with TBI often leads physicians to withhold pharmacological thromboprophylaxis. The American College of Chest Physician guidelines do not specifically address DVT prophylaxis in patients with traumatic brain injury ${ }^{2}$. To help clarify the practice standards to prevent VTE events in the TBI population, we performed a comprehensive systemic review of the literature.

\section{Methods}

The protocol for the review was developed and posted online following guidelines for systematic reviews ${ }^{3,4}$. Additional methodological details are available in our evidence report prepared for the Agency for Healthcare Research and Quality (AHRQ) .

\section{Data sources and search}

The following databases were searched in July 2012 for primary studies: MEDLINE ${ }^{\circledR}$, EMBASE $^{\circledR}$, SCOPUS, CINAHL, International Pharmaceutical Abstracts, clinicaltrial.gov, and the Cochrane Library. An analytic framework depicting our population of interest, interventions tested for prevention of VTE, intermediate and patient-oriented outcomes of treatment, as well as the harms of the interventions was developed ${ }^{3}$.

\section{Study selection}

Titles were reviewed followed by abstracts to identify randomized controlled trials (RCTs) or observational studies with comparison groups reporting on the effectiveness or safety of VTE prevention in TBI patients. Two investigators independently reviewed abstracts meeting our inclusion criteria; abstracts were excluded if both reviewers agreed that the article met one or more of the exclusion criteria (Table 1).

\section{Data abstraction and quality assessment}

Evidence Partners 2010 web-based database management program, DistillerSR, was used to manage the screening and review process. Standardized forms for data extraction from the articles were created. Paired investigators reviewed all extracted data.

The risk of bias was assessed independently and in duplicate, using the Downs and Black instrument ${ }^{6}$. Ten items that were most relevant to this review were prioritized in our assessment of risk of bias. Studies were assessed to have a low risk of bias if all of the following were true: the article completely described the hypothesis, the outcomes (in the introduction or methods section), the characteristics of the included subjects, the distribution of the potential confounders in each group, the interventions and comparisons (if relevant) the main findings, adverse events, and characteristics of the subjects lost to follow up. Additionally, we judged studies to be at low risk of bias if they randomized subjects to the intervention and concealed the assignment until randomization was complete, and if they attempted to blind the study participants and to blind those who measured the main outcomes. By this system, non-randomized studies could only be at moderate or high risk of bias. Studies were rated as having a moderate risk of bias if one of those items was not true, even if all of the others were true, or if the reporting on the distribution of potential confounders in each group was at least partially done. If two of the elements were not true, studies were rated to have a high risk of bias.

\section{Data synthesis and analysis}

A detailed set of evidence tables was created containing all information abstracted from eligible studies. Given the substantial statistical and clinical heterogeneity, we do not report pooled results but display the individual magnitude of effect and statistical significance for the individual studies.

\section{Outcomes assessed}

The effectiveness of pharmacological and mechanical strategies in preventing patient-oriented outcomes such as VTE, deep vein thrombosis (DVT) and pulmonary embolism (PE), mortality and progression of intracranial hemorrhage.

\section{Grading the evidence and applicability}

The quantity, quality, and consistency of the best available evidence was graded by adapting an evidence-grading scheme recommended in the Agency for Healthcare Research and Quality: Methods Guide for Conducting Comparative Effectiveness Reviews?.

\section{Results}

The literature search identified 30902 citations. After necessary exclusions and triage to other topics, 12 articles were included for this review (Figure 1).

\section{Study characteristics}

Seven studies that evaluated the effectiveness of pharmacological and mechanical strategies to prevent VTE in hospitalized patients with TBI were identified ${ }^{8-14}$, four that evaluated the optimal timing of initiation of pharmacological prophylaxis ${ }^{1,15-17}$ and one study that evaluated both ${ }^{18}$. Most of the studies were conducted in North America $^{1,8,9,11-18}$. Two RCTs were included in this review ${ }^{10,14}$. The remaining were cohort studies; nine retrospective studies $1,8,9,11,13,15-18$ and one prospective ${ }^{12}$. The majority of studies included patients admitted in level 1 trauma centers.

\section{Participant characteristics}

The number of participants in the included studies ranged from 32 to 812 ; the mean age of the participants ranged from 36 to 47 years. The Injury Severity Score (ISS) of TBI patients was reported in eight studies; the mean ranged from 15.7 to 33.8 indicating severe multi-system trauma ${ }^{8-12,14,15,18}$. The ethnicity or race of the participants was not reported in any study (Table 2).

\section{Intervention characteristics}

Eight studies were included to assess the effectiveness and safety of pharmacological and mechanical interventions to prevent VTE 
Table 1. Inclusion/Exclusion criteria.

\begin{tabular}{|c|c|c|}
\hline & Inclusion & Exclusion \\
\hline Populations & $\begin{array}{l}\text { - Human subjects (only) } \\
\text { - Patients with traumatic brain injury }\end{array}$ & 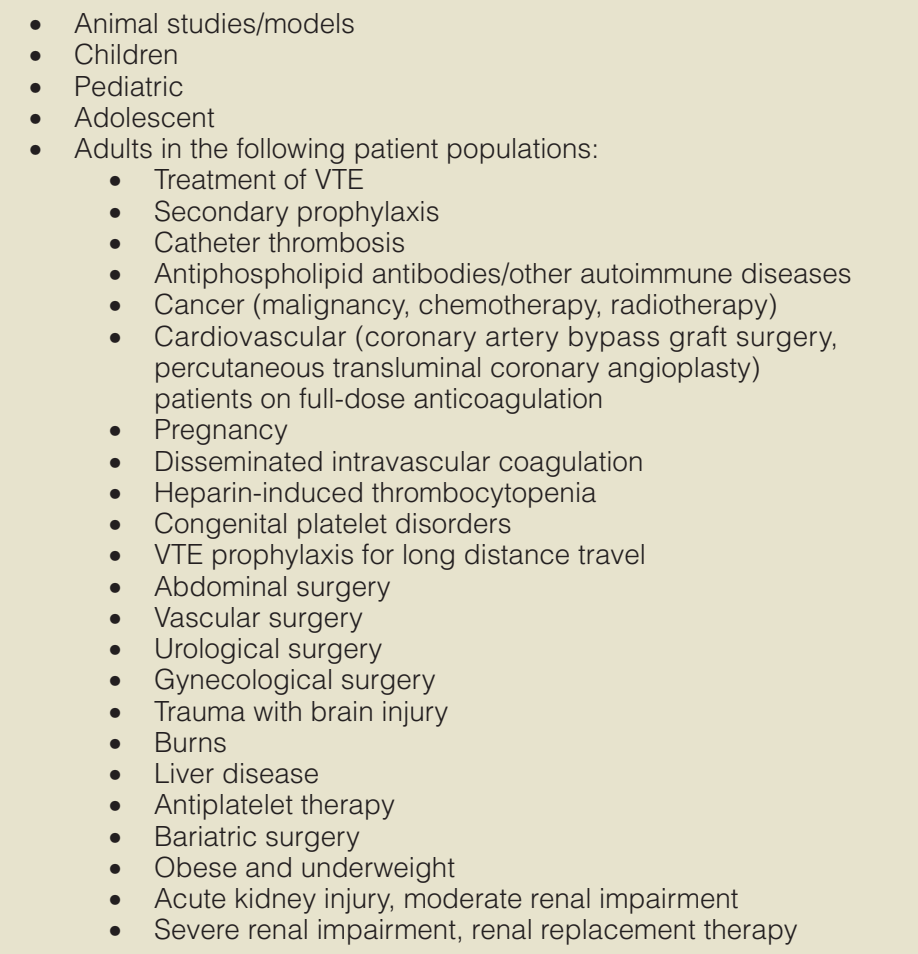 \\
\hline Intervention & $\begin{array}{l}\text { Studies that evaluate pharmacological interventions } \\
\text { or mechanical devices }\end{array}$ & $\begin{array}{l}\text { Studies of agents that have not been approved for thromboprophylaxis } \\
\text { in the United States or interventions not available in the United States will } \\
\text { not be evaluated }\end{array}$ \\
\hline Outcomes & $\begin{array}{l}\text { - Symptomatic deep vein thrombosis } \\
\text { - } \text { Symptomatic pulmonary embolism } \\
\text { - } \text { Post-thrombotic syndrome } \\
\text { - } \quad \text { Quality of life } \\
\text { - } \quad \text { Length of hospital stay } \\
\text { - } \text { Bleeding (major, minor) } \\
\text { - } \text { Allergic reaction } \\
\text { - } \quad \text { Inechanical device complications } \\
\text { - Infections }\end{array}$ & No data on relevant outcomes of interest \\
\hline $\begin{array}{l}\text { Type of } \\
\text { study }\end{array}$ & $\begin{array}{l}\text { - Randomized controlled trials } \\
\text { - } \quad \text { Retrospective cohort studies } \\
\text { - } \quad \text { Unco-control studies } \\
\text { - Case reports of device complications } \\
\quad \text { than the known complications of bleeding } \\
\text { and heparin-induced thrombocytopenia }\end{array}$ & $\begin{array}{l}\text { - } \text { Case reports of efficacy } \\
\text { - } \text { Case reports of bleeding or heparin-induced thrombocytopenia } \\
\text { - In vitro studies pharmacologic strategies } \\
\text { - } \text { Animal studies } \\
\text { - } \text { Most-effectiveness studies } \\
\text { - Risk assessment studies } \\
\text { - Registries without descriptions of interventions } \\
\text { - } \text { - Ecolognostic studies } \\
\text { - Time-series designs } \\
\text { - No original data, commentary, or editorial } \\
\text { - Systematic reviews and meta-analysis }\end{array}$ \\
\hline
\end{tabular}




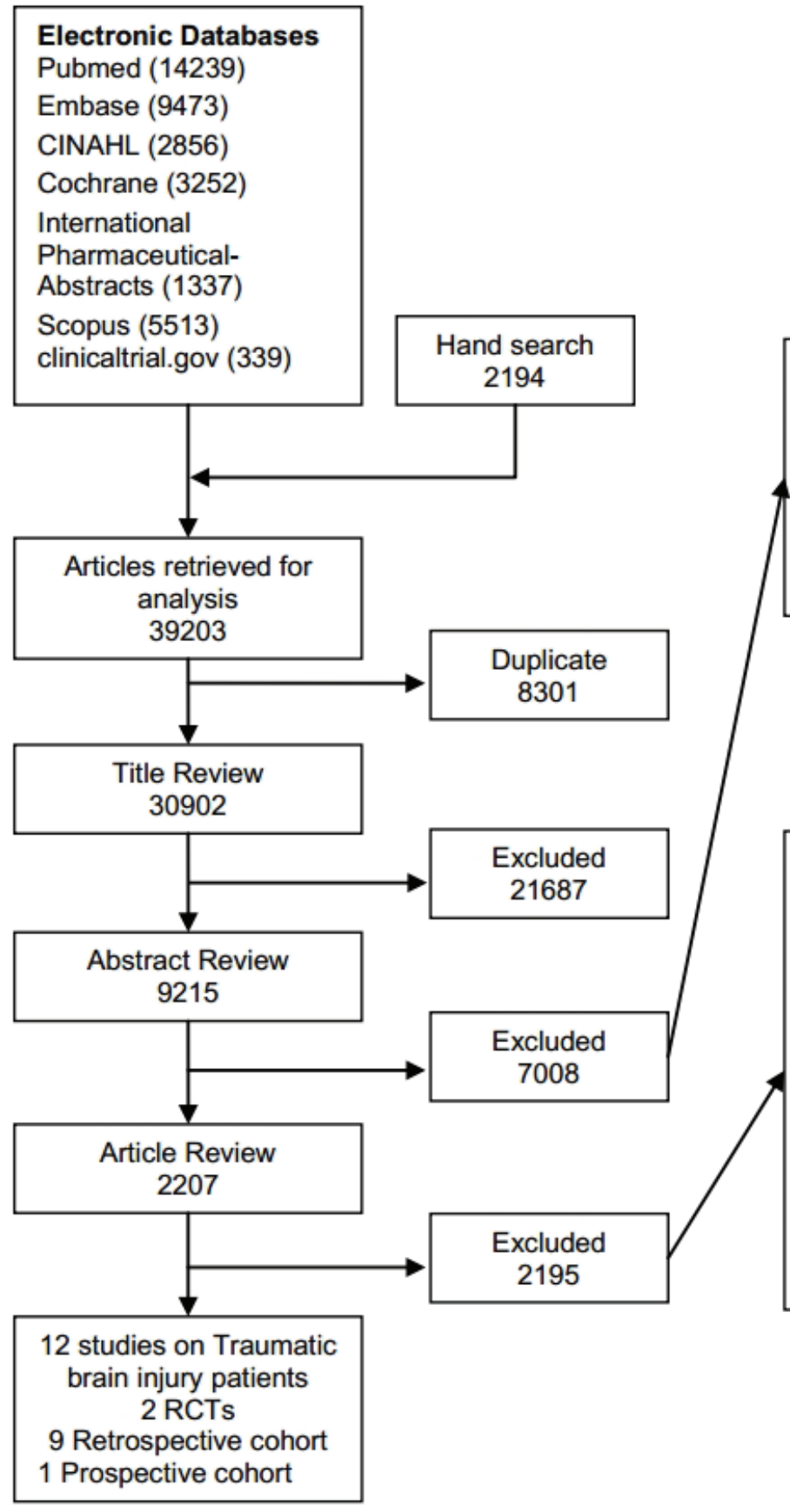

Figure 1. Summary of the literature search.

in patients with traumatic brain injury ${ }^{8-14,18}$. The interventions compared in these studies were highly heterogeneous; studies varied in drugs compared, the dosages and timing of initiation of therapy. Many studies had a control group in which active therapy was withheld from participants. The dose of pharmacological drugs used was reported in five studies; dalteparin was administered as $5000 \mathrm{U}$ once daily. Unfractionated heparin (UFH) as $5000 \mathrm{U}$ thrice daily, and enoxaparin as $30 \mathrm{mg}$ twice daily or $40 \mathrm{mg}$ daily.

\section{Reasons for Exclusion at Abstract Review Level*}

No original data $=4150$

Does not evaluate a population of interest $=1401$

Drug is not available in the U.S. $=207$

Not conducted in humans $=77$

Treatment of VTE $=557$

Not relevant to key questions $=3218$

Other $=463$
Reasons for Exclusion at Article Review Level`

No original data $=253$

Not conducted in humans $=6$

Does not evaluate a population of interest $=976$

Treatment of VTE $=135$

Comparator drug is not available in the U.S. and intervention arm has no data on subgroup $=26$

Subgroup data is not available for our special populations= 713

Case report of known complications of drugs (e.g. Bleeding, HIT) $=11$

Not relevant to key questions $=547$

Other $=173$

Relevant to Key Questions other than traumatic brain injury $=125$
Five studies independently assessed the optimal timing of the initiation of chemoprophylaxis in the same population ${ }^{1,15-18}$. Although enoxaparin and UFH were the only pharmacological agents employed in these studies, two studies were unclear about the pharmacological agents used and were classified as "any heparin" intervention $^{16,17}$. Four out of five studies compared the effectiveness and safety of pharmacoprophylaxis in preventing VTE when initiated less than 72 hours (early prophylaxis) of hospital admission versus greater than 72 hours (late prophylaxis). 
Table 2. Study characteristics.

\begin{tabular}{|c|c|c|c|c|c|c|c|c|c|c|}
\hline \multicolumn{11}{|l|}{ Drug versus control } \\
\hline \multirow[b]{2}{*}{ Study } & \multirow[b]{2}{*}{ Design } & \multirow[b]{2}{*}{ Comparison } & \multicolumn{2}{|c|}{ Patients, N } & \multicolumn{2}{|c|}{ Mean Age (yrs) } & \multicolumn{2}{|c|}{ Male (\%) } & \multicolumn{2}{|c|}{$\begin{array}{l}\text { Mean ISS } \\
\text { Scores }\end{array}$} \\
\hline & & & Drug & Control & Drug & Control & Drug & Control & Drug & Control \\
\hline *Minshall et al., 2011 & RETRO & Enoxaparin vs. Control & 158 & 57 & 41.2 & 38.3 & 75 & 69 & 29 & 30.9 \\
\hline Salottolo et al., 2010 & RETRO & Enoxaparin vs. Control & 255 & 225 & 48 & 59.5 & 64.3 & 58.5 & 21 & 16 \\
\hline Phelan et al., 2010 & $\mathrm{RCT}$ & Enoxaparin vs. Placebo & 34 & 28 & 40.7 & 42.6 & 64 & 57 & 17.3 & 15.7 \\
\hline Kurtoglu et al., 2004 & $\mathrm{RCT}$ & Enoxaparin vs. SCD & 60 & 60 & $37.1^{*}$ & $37.1^{*}$ & $39.2^{*}$ & $39.2^{*}$ & 19.5 & 18.3 \\
\hline *Minshall et al., 2011 & RETRO & UFH vs. Control & 171 & 57 & 42 & 38.3 & 78 & 69 & 33.8 & 30.9 \\
\hline Scudday et al., 2010 & RETRO & UFH vs. Control & 402 & 410 & 45.2 & 51.5 & 69 & 69 & 23.8 & 16.6 \\
\hline \multicolumn{11}{|l|}{ Drug versus drug } \\
\hline & & & \multicolumn{2}{|c|}{ Patients, N } & \multicolumn{2}{|c|}{ Mean Age (yrs) } & \multicolumn{2}{|c|}{ Male (\%) } & \multicolumn{2}{|c|}{$\begin{array}{l}\text { Mean ISS } \\
\text { Scores }\end{array}$} \\
\hline Study & Design & Comparison & Drug 1 & Drug 2 & Drug 1 & Drug 2 & Drug 1 & Drug 2 & Drug 1 & Drug 2 \\
\hline Dudley et al., 2010 & RETRO & Dalteparin vs. Enoxaparin & 159 & 128 & 45.9 & 47.4 & 72.3 & 77.3 & 35 & 31.3 \\
\hline *Minshall et al., 2011 & RETRO & UFH vs. Enoxaparin & 171 & 158 & 42 & 41.2 & 78 & 75 & 33.8 & 29 \\
\hline \multicolumn{11}{|l|}{ SCD versus control } \\
\hline & & & \multicolumn{2}{|c|}{ Patients, N } & \multicolumn{2}{|c|}{ Mean Age (yrs) } & \multicolumn{2}{|c|}{ Male (\%) } & \multicolumn{2}{|c|}{$\begin{array}{l}\text { Mean ISS } \\
\text { Scores }\end{array}$} \\
\hline Study & Design & Comparison & SCD & Control & SCD & Control & SCD & Control & SCD & Control \\
\hline Gersin et al., 1992 & PC & SCD vs. Control & 14 & 18 & 38.3 & 36.1 & 71.4 & 77.8 & 30.5 & 32.1 \\
\hline \multicolumn{11}{|c|}{ Drug $<72$ hrs versus $>72$ hrs } \\
\hline & & & \multicolumn{2}{|c|}{ Patients, N } & \multicolumn{2}{|c|}{ Mean Age (yrs) } & \multicolumn{2}{|c|}{ Male (\%) } & \multicolumn{2}{|c|}{$\begin{array}{l}\text { Mean ISS } \\
\text { Scores }\end{array}$} \\
\hline Study & Design & Comparison & $<72 \mathrm{~h}$ & $>72 \mathrm{~h}$ & $<72 \mathrm{~h}$ & $>72 \mathrm{~h}$ & $<72 \mathrm{~h}$ & $>72 \mathrm{~h}$ & $<72 \mathrm{~h}$ & $>72 \mathrm{~h}$ \\
\hline Koehler et al., 2011 & RETRO & Enoxaparin & 268 & 401 & 39.8 & 40.2 & 69 & 75 & 27.8 & 29.4 \\
\hline Salottolo et al., 2010 & RETRO & Enoxaparin & 108 & 147 & NR & NR & NR & NR & NR & NR \\
\hline Kim et al., 2002 & RETRO & UFH & 47 & 17 & 37.7 & 44 & NR & NR & 30.7 & 35.7 \\
\hline Depew et al., 2008 & RETRO & Any heparin & 29 & 41 & NR & NR & NR & NR & NR & NR \\
\hline
\end{tabular}

*Study has three arms, we have shown data for all comparisons individually; UFH=Unfractionated heparin; SCD=Sequential Compression Devices; ISS=Injury Severity Score; NR=Not Reported; RCT=Randomized Controlled Trial; PC=Prospective Cohort; RETRO=Retrospective Cohort; ${ }^{\ddagger}$ Mean reported for overall group.

There were no studies that assessed the effectiveness of inferior vena cava filters in preventing PE in TBI patients.

\section{Ascertainment of VTE}

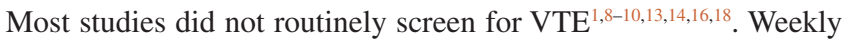
surveillance using duplex ultrasound examination was carried out in four studies ${ }^{11,12,15,17}$, although two of these studies performed it in high risk patients exclusively ${ }^{11,17}$.

\section{Outcomes}

Venous thromboembolism. Five studies assessed the effectiveness of pharmacological agents in preventing VTE in patients with $\mathrm{TBI}^{8,11-13,18}$. One study demonstrated lower rates of VTE in the UFH group compared to the control group (3\% vs. $1 \%$, respectively, $\mathrm{p}=0.019)^{11}$; two studies showed increased rates of VTE in the enoxaparin and sequential compression devices group compared to the control group (enoxaparin vs. control, $3.9 \%$ vs. $2.2 \%$, $\mathrm{p}=0.29$; Sequential compression devices (SCD) vs. control, $28.6 \%$ vs. $22.2 \%, \mathrm{p}=0.7)^{12,18}$, while the last study demonstrated no difference in rates of VTE between dalteparin and control groups (0\% vs. $0 \%)^{13}$. Head-to-head comparison available in a study demonstrated marginally increased rates of venous thromboses in patients treated with dalteparin compared to those treated with enoxaparin $(7.5 \%$ vs. $7.0 \%$, p value not significant $)^{8}$.

A single study demonstrated increased rates of VTE with early enoxaparin prophylaxis when compared to late prophylaxis. (5.56\% vs. $2.72 \%$ percent, Odds ratio (OR) $2.10, \mathrm{p}=0.26)^{18}$ (Table 3).

Overall, the evidence was concluded to be insufficient to comment on the effectiveness and optimal timing of initiation of VTE prophylaxes in TBI patients (Table 4). 
Table 3. Patient-oriented outcomes.

\begin{tabular}{|c|c|c|c|c|c|c|c|c|c|c|c|}
\hline \multicolumn{12}{|l|}{ Drug versus control } \\
\hline \multirow[b]{2}{*}{ Study } & \multirow[b]{2}{*}{ Comparison } & \multicolumn{2}{|c|}{ Patients, N } & \multicolumn{2}{|c|}{ \% Total DVT } & \multicolumn{2}{|c|}{$\%$ Total PE } & \multicolumn{2}{|c|}{$\%$ Total mortality } & \multicolumn{2}{|c|}{$\begin{array}{c}\% \text { ICH } \\
\text { progression }\end{array}$} \\
\hline & & Drug & Control & Drug & Control & Drug & Control & Drug & Control & Drug & Control \\
\hline *Minshall et al., 2011 & $\begin{array}{l}\text { Enoxaparin vs. } \\
\text { Control }\end{array}$ & 158 & 57 & 1 & 2 & 0 & 2 & 5 & 47 & 5 & NR \\
\hline Salottolo et al., 2010 & $\begin{array}{l}\text { Enoxaparin vs. } \\
\text { Control }\end{array}$ & 255 & 225 & NR & NR & NR & NR & NR & NR & NR & 8.4 \\
\hline Phelan et al., 2010 & $\begin{array}{l}\text { Enoxaparin vs. } \\
\text { Placebo }\end{array}$ & 34 & 28 & 0 & 3.6 & 0 & 0 & NR & NR & 5.9 & 3.6 \\
\hline Kurtoglu et al., 2004 & $\begin{array}{l}\text { Enoxaparin vs. } \\
\text { SCD }\end{array}$ & 60 & 60 & $5^{\#}$ & $6.6^{\#}$ & $6.6^{\pi, \Phi}$ & $3.3^{\Uparrow, \Phi}$ & 13.3 & 11.6 & 1.6 & 1.6 \\
\hline *Minshall et al., 2011 & UFH vs. Control & 171 & 57 & 1 & 2 & 4 & 2 & 15.8 & 47 & 12 & NR \\
\hline Scudday et al., 2010 & UFH vs. Control & 402 & 410 & NR & NR & NR & NR & 0.8 & 3.7 & $3 \pi$ & $6 \pi$ \\
\hline Sadeh et al., 2012 & $\begin{array}{l}\text { Dalteparin vs. } \\
\text { Control }\end{array}$ & 93 & 29 & 0 & 0 & 0 & 0 & NR & NR & 0 & 0 \\
\hline \multicolumn{12}{|l|}{ Drug versus drug } \\
\hline & & \multicolumn{2}{|c|}{ Patients, N } & \multicolumn{2}{|c|}{ \% Total DVT } & \multicolumn{2}{|c|}{$\%$ Total PE } & \multicolumn{2}{|c|}{$\%$ Total mortality } & \multicolumn{2}{|c|}{$\begin{array}{c}\% \text { ICH } \\
\text { progression }\end{array}$} \\
\hline Study & Comparison & Drug 1 & Drug 2 & Drug 1 & Drug 2 & Drug 1 & Drug 2 & Drug 1 & Drug 2 & Drug 1 & Drug 2 \\
\hline Dudley et al., 2010 & $\begin{array}{l}\text { Dalteparin vs. } \\
\text { Enoxaparin }\end{array}$ & 159 & 128 & NR & NR & 0.6 & NR & NR & NR & 0 & 0.01 \\
\hline *Minshall et al., 2011 & $\begin{array}{l}\text { UFH vs. } \\
\text { Enoxaparin }\end{array}$ & 171 & 158 & 1 & 1 & $4 \pi$ & 0 ? & 15.8 & 5 & $12^{n}$ & $5 \pi$ \\
\hline \multicolumn{12}{|l|}{$S C D$ versus control } \\
\hline & & \multicolumn{2}{|c|}{ Patients, N } & \multicolumn{2}{|c|}{ \% Total DVT } & \multicolumn{2}{|c|}{$\%$ Total PE } & \multicolumn{2}{|c|}{$\%$ Total mortality } & \multicolumn{2}{|c|}{$\begin{array}{c}\% \mathrm{ICH} \\
\text { progression }\end{array}$} \\
\hline Study & Comparison & SCD & Control & SCD & Control & SCD & Control & SCD & Control & SCD & Control \\
\hline Gersin et al., 1992 & $\begin{array}{l}\text { SCD vs. } \\
\text { Control }\end{array}$ & 14 & 18 & 0 & 11.1 & 28.6 & 11.1 & NR & NR & NR & NR \\
\hline \multicolumn{12}{|c|}{ Drug $<72 \mathrm{hrs}$ versus $>72 \mathrm{hrs}$} \\
\hline & & \multicolumn{2}{|c|}{ Patients, N } & \multicolumn{2}{|c|}{ \% Total DVT } & \multicolumn{2}{|c|}{$\%$ Total PE } & \multicolumn{2}{|c|}{$\%$ Total mortality } & \multicolumn{2}{|c|}{$\begin{array}{c}\% \text { ICH } \\
\text { progression }\end{array}$} \\
\hline Study & Comparison & $<72 \mathrm{~h}$ & $>72 \mathrm{~h}$ & $<72 \mathrm{~h}$ & $>72 \mathrm{~h}$ & $<72 \mathrm{~h}$ & $>72 \mathrm{~h}$ & $<72 \mathrm{~h}$ & $>72 \mathrm{~h}$ & $<72 \mathrm{~h}$ & $>72 \mathrm{~h}$ \\
\hline Koehler et al., 2011 & Enoxaparin & 268 & 401 & NR & NR & $1.5^{\#}$ & $2.2^{\#}$ & NR & NR & $1.5^{\#}$ & $1.5^{\#}$ \\
\hline Salottolo et al., 2010 & Enoxaparin & 108 & 147 & NR & NR & NR & NR & NR & NR & $6.5^{\#}$ & $14.3^{\#}$ \\
\hline Kim et al., 2002 & UFH & 47 & 17 & $4.3^{\#}$ & $5.9^{\#}$ & $4.3^{\#}$ & $\mathrm{O}^{\#}$ & $8.5^{\#}$ & $5.9^{\#}$ & NR & NR \\
\hline Depew et al., 2008 & Any heparin & 29 & 41 & 10.4 & 14.6 & 3.5 & 0 & NR & NR & 3.5 & 3.8 \\
\hline
\end{tabular}

*Study has three arms; UFH=Unfractionated heparin; SCD=Sequential Compression devices; DVT=Deep vein thrombosis; PE=Pulmonary embolism;

$\mathrm{ICH}=$ intracranial hemorrhage; N=Number; NR=Not Reported; \#p value not significant; " $p$ value significant; ${ }^{\Phi}$ - Of the total PE, $6.6 \%$ in the enoxaparin arm and

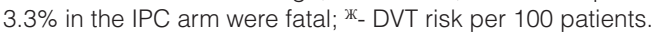

Deep vein thrombosis. Four studies were included to evaluate the efficacy of enoxaparin, UFH and sequential compression devices in preventing the development of DVT in patients with $\mathrm{TBI}^{9,10,12,14}$. A single study demonstrated reduced rates of DVT in enoxaparin and UFH heparin groups compared to control (1\% vs. $1 \%$ vs. $2 \%$ respectively, $\mathrm{p}$ value not reported $)^{9}$. Two more studies demonstrated lower rates of DVT in patients treated with enoxaparin compared to those treated with placebo and sequential compression devices $(0 \%$ vs. $3.6 \%, \mathrm{p}=0.45$ and $5 \%$ vs. $6.6 \%, \mathrm{p}=0.07)^{10,14}$. In contrast to this, a fourth study demonstrated that patients treated with sequential compression devices experienced fewer events when compared to a control group (0\% vs. $11.1 \%)^{12}$.

In two "any heparin" studies, the rates of DVT were consistently higher in the late prophylaxis group ${ }^{16,17}$. The same was observed in patients treated with UFH; rates of DVT were higher when UFH 


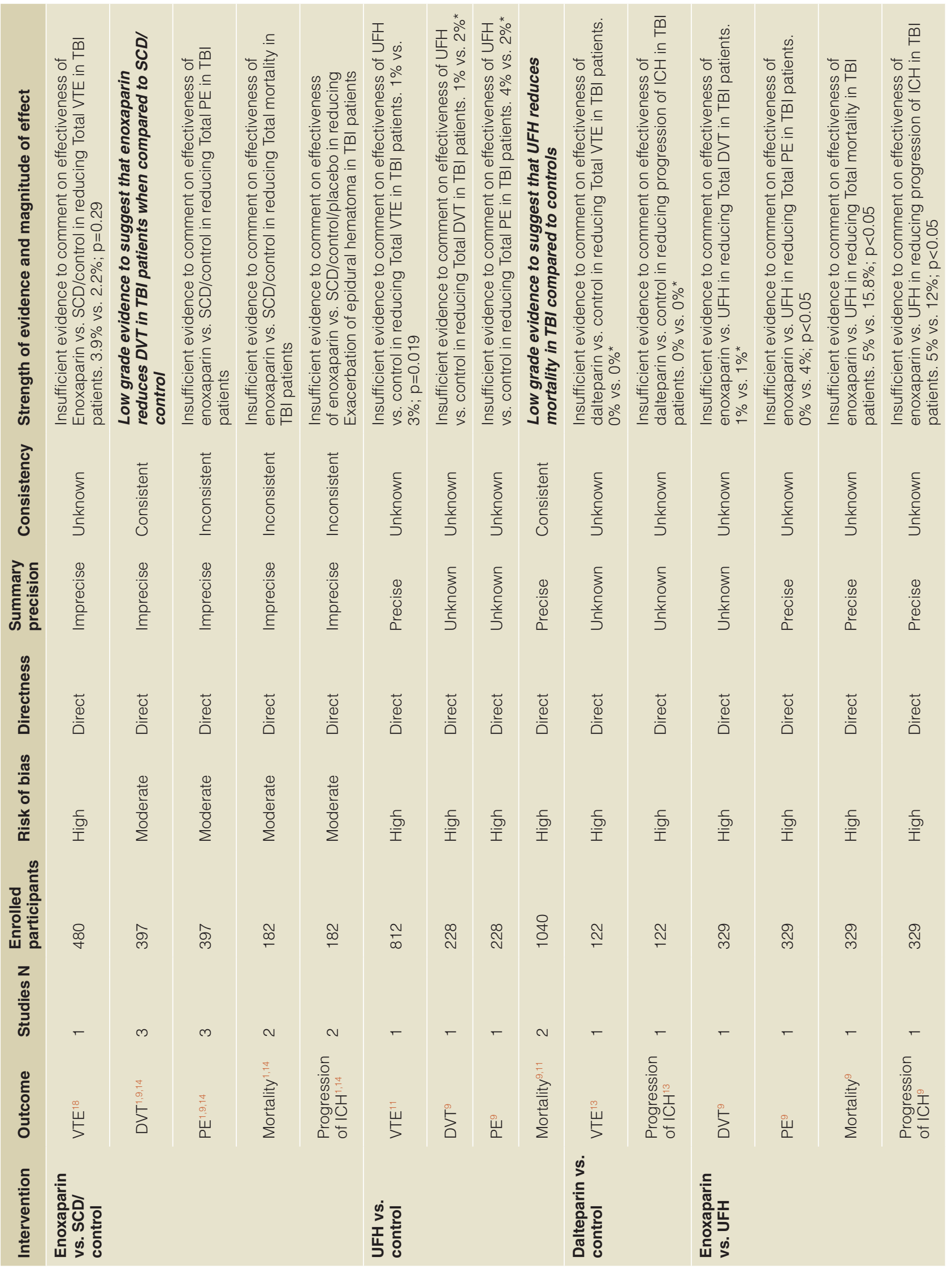




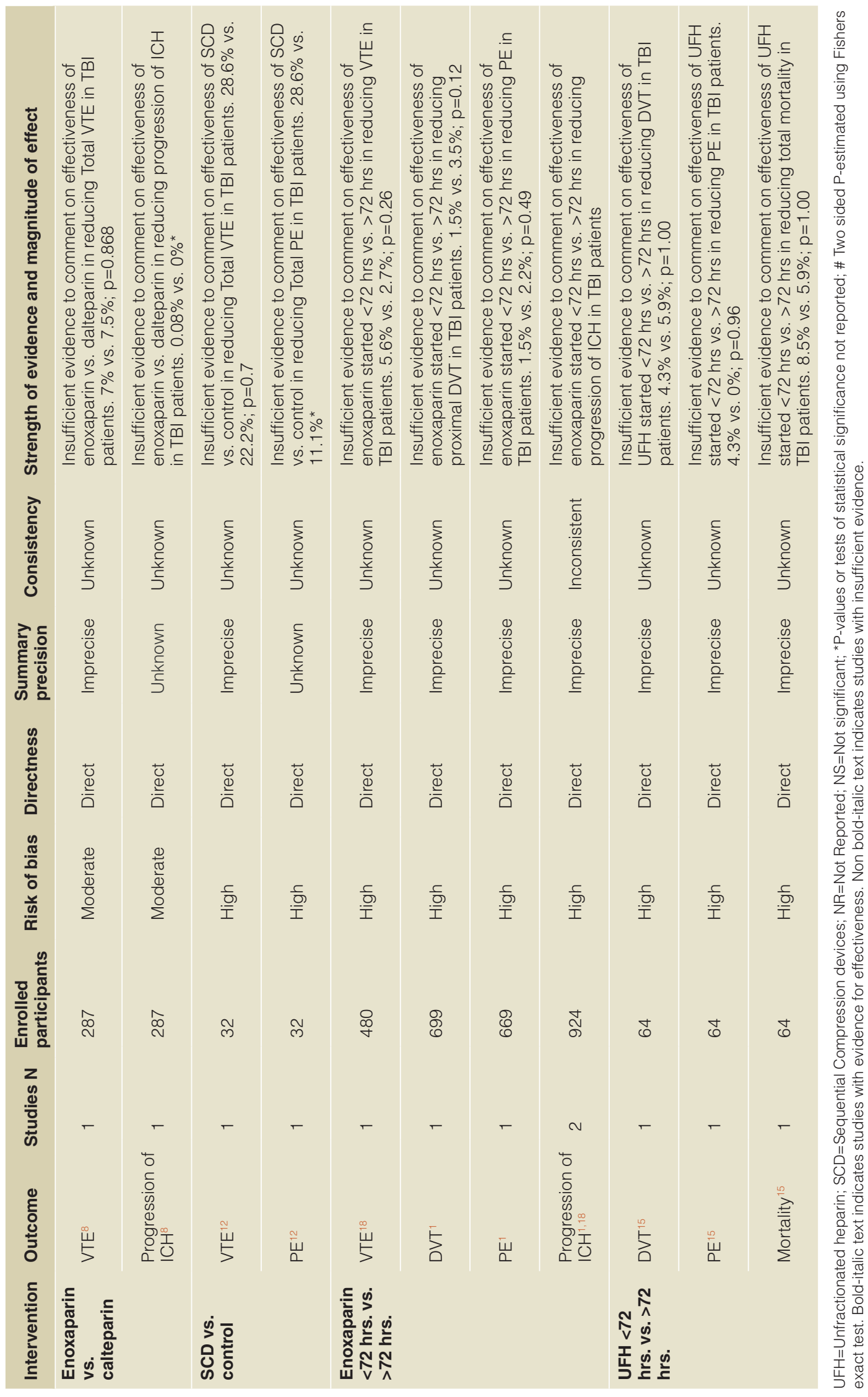


was commenced later than 72 hours $(4.3 \%$ vs. $5.9 \%$, p value not significant) ${ }^{15}$ (Table 3 ).

Three individual studies demonstrated that rates of DVT were lower in patients treated with enoxaparin when compared to controls or patients treated with sequential compression devices only ${ }^{9,10,14}$. Consistent, direct, yet imprecise results, which included one RCT with a low risk of bias, led to the conclusion that low-grade evidence supported the effectiveness of enoxaparin over control/ sequential compression devices in reducing DVT in hospitalized patients with TBI. However, the evidence is insufficient to comment on the optimal timing of initiation of chemoprophylaxis in the same population (Table 4).

Pulmonary embolism. Five out of the eight included studies assessed the effectiveness of prophylaxis with enoxaparin, dalteparin, UFH and sequential compression devices in preventing development of $\mathrm{PE}$ in patients hospitalized with TBI. The results of these studies were equivocal. One study demonstrated that patients treated with enoxaparin failed to develop PE, whilst those in the control and UFH intervention groups did, the rate being lower in the control group 9 . In contrast, a RCT demonstrated that there was no difference in rates of PE in enoxaparin-treated patients and controls $(0 \%$ vs. $0 \%)^{14}$. Two studies showed varying outcomes in patients treated with sequential compression devices only; a RCT demonstrated lower rates of PE, all of which were fatal, in this group compared to treatment with enoxaparin $(3.3 \% \text { vs. } 6.6 \%, \mathrm{p}=0.04)^{10}$. However, in another study, the patients in the sequential compression devices intervention group were reported to have experienced an increase in pulmonary embolic events in comparison to control patients $(28.6 \%$ vs. $11.1 \%$, p value not reported $)^{12}$. The last study reported the rate of development of PE in patients treated with dalteparin only, limiting an assessment of comparative effectiveness ${ }^{8}$.

Optimal timing of initiation of chemoprophylaxis in TBI populations to prevent development of PE was analyzed in three studies. Two studies demonstrated increased incidence of PE with early prophylaxis $(3.5 \%$ vs. $0 \%$ and $4.3 \%$ vs. $0 \%)$, whereas in the third study, patients treated with enoxaparin within 72 hours of admission experienced fewer pulmonary embolic events (1.5\% vs. $2.2 \%$, respectively, $\mathrm{p}=0.49)^{1,17,18}$ (Table 3 ).

The evidence was concluded to be insufficient to comment on the effectiveness and optimal timing of initiation of prophylaxes in preventing PE in TBI patients (Table 4).

Total mortality. Three studies included in this review evaluated the efficacy of prophylaxis with UFH or enoxaparin versus no prophylaxis or treatment with sequential compression devices only. Two studies uniformly demonstrated increased mortality in control groups when compared to patients treated with enoxaparin and $\mathrm{UFH}^{9,10}$. However, the third study demonstrated that rates of mortality were increased in patients treated with enoxaparin when compared to those prescribed sequential compression devices only $(13.3 \% \text { vs. } 11.6 \%, \mathrm{p}=0.08)^{10}$.

A single cohort study reported increased deaths with early UFH prophylaxis when compared to late prophylaxis (8.5\% vs. $5.9 \%$, $\mathrm{p}=1.0)^{15}$ (Table 3).
Low grade evidence supported the effectiveness of UFH over no pharmacoprophylaxis in reducing total mortality in patients hospitalized with traumatic brain injury (Table 4).

Progression of intracranial hemorrhage. The rates of progression of intracranial hemorrhage resulting from prophylaxis with dalteparin, enoxaparin, or UFH were reported in six studies ${ }^{8-11,13,14}$. Two studies reported that there was no difference in rates of progression of intracranial hemorrhage between the control or sequential compression devices only group and the pharmacoprophylaxis (enoxaparin and dalteparin) group ${ }^{10,13}$. Another set of two studies that compared prophylaxis with UFH and enoxaparin to control or placebo demonstrated equivocal results ${ }^{11,14}$; patients treated with UFH had lower rates of progression of intracranial hemorrhage, while those treated with enoxaparin had higher rates. Two other studies demonstrated head-to-head comparisons of two pharmacological agents. According to one study, patients treated with enoxaparin and dalteparin had comparable rates of intracranial bleeding $(0.001 \% \text { vs. } 0 \%)^{8}$, while the other demonstrated a statistically significant increase in intracranial bleed in patients treated with UFH compared to those treated with enoxaparin (12\% vs. $5 \%, \mathrm{p}<0.05)^{9}$.

Three studies evaluating the optimal timing of initiation of pharmacoprophylaxis reported on rates of progression of intracranial hemorrhage in TBI populations ${ }^{1,15,18}$. Even though all three studies reported increased rates of intracranial hemorrhage when prophylaxis was initiated with enoxaparin or any other heparin after 72 hours of admission, the increase was only minimal in two studies $(3.5 \%$ vs. $3.8 \% ; 1.46 \%$ vs. $1.54 \%$ ) (Table 3 ).

Overall, the evidence was insufficient to comment on the effect of pharmacological and mechanical prophylaxis and timing of initiation of pharmacoprophylaxis on progression of intracranial bleeding in TBI patients (Table 4).

\section{Risk of bias}

Of the twelve studies included in this review, only one RCT was at a low risk of bias ${ }^{14}$. With the exception of a single cohort study that was at a moderate risk of bias ${ }^{8}$, ten were estimated to be high risk of bias studies. Most cohort studies had incomplete descriptions of the important confounders and a lack of adjustment for differences between groups. They also had incomplete accounts of losses to follow-up. All of these are important confounders and threaten the internal validity of these studies.

\section{Applicability}

The participants that these studies recruited were typical of participants admitted to other trauma centers and hence findings are generalizable. The studies were generally representative of patients with TBI in the USA. Gender was inconsistently reported, thus we could not assess the applicability of these findings to females. We did not have details to assess the applicability of this evidence to other racial groups since the studies inconsistently reported on ethnicity or race. Some studies excluded patients with previous VTE ${ }^{1,10}$ as well as those at higher risk of bleeding, such as those with low platelet counts ${ }^{1,10,14,15}$, limiting generalizability to these high-risk subgroups. 


\section{Discussion}

We found low-grade evidence that enoxaparin reduced rates of DVT and UFH reduced rates of mortality when compared to no pharmacoprophylaxis in TBI patients. The evidence was insufficient to comment on the effectiveness and safety of remaining comparators. Evidence was also insufficient for assessment of optimal timing of initiation of pharmacoprophylaxis for all comparators and outcomes.

We found only two RCTs that addressed VTE prophylaxis in patients with TBI. The remaining studies were single-center cohort studies, the majority of which were retrospective, having high risk of bias. Although the studies in this review asked similar questions (i.e., enoxaparin vs. heparin, pharmacologic prophylaxis vs. SCDs) and had similar patient populations, the scarcity of good quality studies with low risk of biases prevents definitive conclusions.

We identified a retrospective cohort study by Kwiatt et al. with a moderate risk of bias, published after our search cutoff date that evaluated the effectiveness of enoxaparin compared to control in reducing venous thrombosis and progression of intracranial hemorrhage in TBI patients ${ }^{19}$. The results of this study were consistent with other studies included in our review that compared enoxaparin with a control or placebo group. This study demonstrated that the rates of venous thrombosis and progression of intracranial hemorrhage were significantly higher in patients treated with enoxaparin compared to patients in the control group (9.1\% vs. $3.1 \%$ and $42 \%$ vs. $24 \%$ respectively, $\mathrm{p}<0.001$ for both outcomes) indicating a potential for more harm than benefit with utilization of enoxaparin in this population. This reiterates the need for good quality studies to establish the effectiveness and safety of VTE prophylaxis in patients with TBI.

Our results should be interpreted in the context of other systematic reviews and existing guidelines. We did not identify any existing systematic reviews about the role of VTE prophylaxis and its optimal timing and initiation in patients with traumatic brain injury. The two organizations, The Eastern Association for the Surgery of Trauma (EAST) and the Brain Trauma Foundation, that provide guidelines for the care of trauma patients and patients with traumatic brain injury, respectively, do not make specific recommendations about DVT prophylaxis in TBI patients. EAST practice guidelines address DVT prophylaxis in the general trauma patient but do not make specific recommendations about patients with brain trauma. In 2007, the Brain Trauma Foundation Guidelines for the Management of Severe Traumatic Brain Injury found no good quality data to support the use of DVT prophylaxis in TBI patients. They found level III evidence for IPC and chemoprophylaxis, while stating that "there is insufficient evidence to support recommendations regarding the preferred agent, dose, or timing of pharmacologic prophylaxis for deep vein thrombosis (DVT)"20.

Additionally, the American College of Chest Physician guidelines do not specifically address DVT prophylaxis in these patients ${ }^{2}$.

\section{Limitations}

Our systematic review identified important weaknesses in the literature. We did not identify high quality RCTs for this review. The majority of observational studies included in this review were at a high risk of bias and did not report on several quality items of interest. The studies were heterogeneous in the definition of VTE and bleeding outcomes precluding any meaningful pooling in a meta-analysis. We also did not find data on several pharmacologic comparisons of interest or details about optimal timing of initiation of prophylaxis in this population. We were unable to assess the possibility of publication bias or selective outcomes reporting and its impact on our findings.

\section{Future research}

Studies among patients with TBI are needed to determine whether pharmacologic DVT prophylaxis should be employed in these patients and the timing of administration. Studies should also determine the role of appropriate classification and severity of TBI when deciding to administer pharmacologic prophylaxis. Our report shows that confounding by indication was a major problem in these studies. Patients at high risk for thrombotic outcomes were more likely to receive prophylaxis and more likely to have events-the treated and untreated patients were not comparable. Future studies should consider the use of appropriate analytic strategies such as instrumental variables that control for unobserved variables if an appropriate instrument can be identified for analysis. High-quality observational studies that control for confounding by indication, such as provider and practice patterns, and confounding by disease severity may be needed as RCTs typically exclude or do not report on these populations.

\section{Conclusion}

Low grade evidence supports the effectiveness of enoxaparin over no pharmacoprophylaxis in reducing the rates of DVT in patients with TBI. Low-grade evidence also supported the safety of UFH over no pharmacoprophylaxis in reducing total mortality in the same population. The evidence was insufficient for the remaining comparators and outcomes assessed such as VTE and PE.

\section{Author contributions}

YC selected articles for inclusion, extracted data, graded the strength of the evidence, drafted the initial manuscript and revised the manuscript. KAS and SS selected articles for inclusion, extracted data, graded the strength of the evidence and reviewed and revised the manuscript. ERH, DJB, KMS and SK selected articles for inclusion, extracted data, graded the strength of the evidence and critically reviewed the manuscript. RS designed the data abstraction forms, coordinated data abstraction and data management, selected articles for inclusion and critically reviewed the manuscript. JBS supervised all steps of the systematic review process and reviewed and revised the manuscript. All authors agreed on the final manuscript for publication.

\section{Competing interests}

Dr Haut is the primary investigator of the Mentored Clinician Scientist Development Award K08 1K08HS017952-01 from the Agency for Healthcare Research and Quality entitled "Does Screening Variability Make DVT an Unreliable Quality Measure of Trauma Care?" Dr Haut receives royalties from Lippincott, Williams, \& 
Wilkins for a book he coauthored (Avoiding Common ICU Errors) and has given expert witness testimony in various medical malpractice cases.

Dr. Brotman reports having been on an advisory boards for the following companies: Canyon Pharmaceuticals, Cubist Pharmaceuticals, Sanofi-Aventis Pharmaceuticals, Bristol-Myers Squibb/ Sanofi Pharmaceuticals Partnership, EMCREG International, Otsuka America Pharmaceutical, Inc., Ortho-McNeil Pharmaceuticals, Johnson \& Johnson. He has consulted for Gerson Lehrman Group. The Dunn Group and Quantia Communications, LLC. He has received research support from Siemens Healthcare Diagnostics (formerly Dade Behring), Agency for Healthcare Research and Quality (AHRQ), Center for Medicare \& Medicaid Services (CMS), and Amerigroup Corporation. He has been an expert witness in various cases addressing clinical decision making and actions of Hospitalists, nurses, and other healthcare professionals.
All other authors report no conflicts of interest.

The authors of this article are responsible for its contents, including any clinical or treatment recommendations. No statement in this article should be construed as an official position of AHRQ or of the U.S. Department of Health and Human Services.

\section{Grant information}

This study was funded by a grant from the Agency for Healthcare Research and Quality (AHRQ), Contract number: HHSA-2902007-10061 I. The AHRQ participated in formulating the key questions and reviewed planned methods and data analyses, as well as interim and final evidence reports. The AHRQ had no role in data collection, data management, data analysis, study selection, quality ratings, or interpretation/synthesis of the evidence.

The funders had no role in study design, data collection and analysis, decision to publish, or preparation of the manuscript.
1. Koehler DM, Shipman J, Davidson MA, et al:: Is early venous thromboembolism prophylaxis safe in trauma patients with intracranial hemorrhage. $J$ Trauma. 2011; 70(2): 324-9.

PubMed Abstract | Publisher Full Text

2. Gould MK, Garcia DA, Wren SM, et al:: American College of Chest Physicians. Prevention of VTE in nonorthopedic surgical patients: Antithrombotic Therapy and Prevention of Thrombosis, 9th ed: American College of Chest Physicians Evidence-Based Clinical Practice Guidelines. Chest. 2012; 141(2 Suppl): E227S-77S.

PubMed Abstract | Publisher Full Text | Free Full Text

3. Comparative Effectiveness of Pharmacologic and Mechanical Prophylaxis of Venous Thromboembolism Among Special Populations - Research Protocol | AHRQ Effective Health Care Program 2012. Reference Source

4. Walther S, Schuetz GM, Hamm B, et al:: [Quality of reporting of systematic reviews and meta-analyses: PRISMA (Preferred Reporting Items for Systematic reviews and Meta-Analyses)]. Rofo. 2011;183(12): 1106-10. PubMed Abstract | Publisher Full Text

5. Singh S, Haut ER, Brotman DJ, et al.: Pharmacological and Mechanical Prophylaxis of Venous Thromboembolism Among Special Populations; Comparative Effectiveness Review. PubMed Abstract

6. Downs SH, Black N: The feasibility of creating a checklist for the assessment of the methodological quality both of randomised and non-randomised studies of health care interventions. J Epidemiol Community Health. 1998; 52(6): 377-84. PubMed Abstract | Publisher Full Text | Free Full Text

7. Methods Guide for Effectiveness and Comparative Effectiveness Reviews. Rockville MD: Agency for Healthcare Research and Quality; August 2011. AHRQ Publication No. 10(11)-EHC063-EF. Chapters Reference Source

8. Dudley RR, Aziz I, Bonnici A, et al:: Early venous thromboembolic event prophylaxis in traumatic brain injury with low-molecular-weight heparin: risks and benefits. J Neurotrauma. 2010; 27(12): 2165-72. PubMed Abstract | Publisher Full Text

9. Minshall CT, Eriksson EA, Leon SM, et al:: Safety and efficacy of heparin or enoxaparin prophylaxis in blunt trauma patients with a head abbreviated injury severity score $>\mathbf{2}$. J Trauma. 2011; 71(2): 396-9. PubMed Abstract | Publisher Full Text

10. Kurtoglu M, Yanar H, Bilsel Y, et al:: Venous thromboembolism prophylaxis after head and spinal trauma: intermittent pneumatic compression devices versus low molecular weight heparin. World J Surg. 2004; 28(8): 807-11. PubMed Abstract | Publisher Full Text
11. Scudday $\mathrm{T}$, Brasel K, Webb T, et al.: Safety and efficacy of prophylactic anticoagulation in patients with traumatic brain injury. J Am Coll Surg. 2011; 213(1): 148-53.

PubMed Abstract | Publisher Full Text

12. Gersin K, Grindlinger GA, Lee V, et al:: The efficacy of sequential compression devices in multiple trauma patients with severe head injury. $J$ Trauma. 1994 37(2): 205-8. PubMed Abstract

13. Saadeh $\mathrm{Y}$, Gohil K, Bill C, et al:: Chemical venous thromboembolic prophylaxis is safe and effective for patients with traumatic brain injury when started 24 hours after the absence of hemorrhage progression on head CT. J Trauma Acute Care Surg. 2012; 73(2): 426-30. PubMed Abstract | Publisher Full Text

14. Phelan HA, Wolf SE, Norwood SH, et al.: A randomized, double-blinded, placebocontrolled pilot trial of anticoagulation in low-risk traumatic brain injury: The Delayed Versus Early Enoxaparin Prophylaxis I (DEEP I) study. J Trauma Acute Care Surg. 2012; 73(6): 1434-41. PubMed Abstract | Publisher Full Text

15. Kim J, Gearhart MM, Zurick A, et al.: Preliminary report on the safety of heparin for deep venous thrombosis prophylaxis after severe head injury. J Trauma. 2002; 53(1): 38-42; discussion 43. PubMed Abstract | Publisher Full Text

16. Reiff DA, Haricharan RN, Bullington NM, et al:: Traumatic brain injury is associated with the development of deep vein thrombosis independent of pharmacological prophylaxis. J Trauma. 2009; 66(5): 1436-40. PubMed Abstract | Publisher Full Text

17. Depew AJ, Hu CK, Nguyen AC, et al:: Thromboembolic prophylaxis in blunt traumatic intracranial hemorrhage: a retrospective review. Am Surg. 2008; 74(10): 906-11.

PubMed Abstract

18. Salottolo K, Offner P, Levy AS, et al.: Interrupted pharmocologic thromboprophylaxis increases venous thromboembolism in traumatic brain injury. J Trauma. 2011; 70(1): 19-24; discussion 25-6. PubMed Abstract | Publisher Full Text

19. Kwiatt ME, Patel MS, Ross SE, et al.: Is low-molecular-weight heparin safe for venous thromboembolism prophylaxis in patients with traumatic brain injury? A Western Trauma Association multicenter study. J Trauma Acute Care Surg. 2012; 73(3): 625-8.

PubMed Abstract | Publisher Full Text

20. Guidelines for the Management of Severe Traumatic Brain Injury 3rd Edition. 2012. Reference Source 


\section{Open Peer Review}

\section{Current Peer Review Status:}

\section{Version 1}

Reviewer Report 08 April 2014

https://doi.org/10.5256/f1000research.1383.r4154

(C) 2014 Steyerberg E et al. This is an open access peer review report distributed under the terms of the Creative Commons Attribution License, which permits unrestricted use, distribution, and reproduction in any medium, provided the original work is properly cited.

\section{Ewout W. Steyerberg}

Department of Public Health, Erasmus Medical Center, Rotterdam, The Netherlands Maryse Cnossen

Erasmus Medical Center, Rotterdam, The Netherlands

The paper is well written and the tables and figures are clear. The conclusion is well based on the results.

There is a recent review that was related to the current review. Phelan (2012) conducted a critical literature review about pharmacologic venous thromboembolism prophylaxis after traumatic brain injury. The method by Phelan was less systematic, and he only included pharmacological prophylaxis (instead of also mechanical). However, 9 of the included studies in this review were also reviewed in the study by Phelan. Overall, the current study is therefore quite similar to the review by Phelan.

The main conclusion remains that further research is urgently needed in this area.

Some specific comments:

\section{Introduction}

The authors state that "this population is at increased risk for VTE due to a combination of factors (i.e. the brain injury itself, other injuries, intensive care unit admission, immobilization, major surgery etc.)". They do not mention a source here. Perhaps a subgroup of TBI patients at risk for VTE, however, not all patients will be at risk (e.g. uncomplicated mTBI patients).

In the introduction I miss some information about pharmacological and mechanical prophylaxis (what is it, when is it used, examples etc).

\section{Methods}

No patient and injury characteristics are mentioned as inclusion criteria, however, GCS may be an important confounding factor in the research question. The search terms and mesh 
terms are not mentioned. It is not mentioned whether papers were excluded if published before a certain date.

In table 1 authors mention a long list of population exclusion criteria. This seems in contrast with the ISS score $>15$ in all studies, indicating multi-system trauma. Some more information is necessary here (how did the authors handle studies in which some of the patients met the exclusion criteria?).

It is not clear to me what is meant by "trauma with brain injury".

Also, underweight and obesity are mentioned as exclusion criteria. How did the authors account for this? BMI is not often reported in studies examining TBI.

\section{Results}

The injury severity score is used to indicate severity. However, this score does not account for severity of TBI. Do the studies report GCS scores?

In the table with study characteristics, the study by Sadeh is not included it seems?

\section{Discussion}

An extra limitation is that the authors excluded studies that were comparing drugs not available in the US $(n=26)$.

Competing Interests: No competing interests were disclosed.

We confirm that we have read this submission and believe that we have an appropriate level of expertise to confirm that it is of an acceptable scientific standard.

Reviewer Report 07 August 2013

https://doi.org/10.5256/f1000research.1383.r1353

(C) 2013 Bar-Or D. This is an open access peer review report distributed under the terms of the Creative Commons Attribution License, which permits unrestricted use, distribution, and reproduction in any medium, provided the original work is properly cited.

\section{David Bar-Or}

Ampio Pharmaceuticals, Greenwood Vlg, CO, USA

The systematic review of Chelladurai et al. on VTE prophylaxis in patients with traumatic brain injury is an excellent review and analysis of the literature on the subject. It reinforces the urgent need for well controlled, prospective studies to assess the safety, efficacy and drug choice for thromboprophylaxis in this group of patients. Timing of intervention, severity and type of injury and associated conditions, interruption of treatment for surgical procedures, effects on the geriatric population and others are variables that would require special attention. The evidence reported in this review, as the authors conclude, supports (although weak) the use of 
thromboprophylaxis in this group of patients. It is probable that a subgroup may benefit more than others and it would be interesting to focus even a retrospective study to such a group.

Competing Interests: No competing interests were disclosed.

I confirm that I have read this submission and believe that I have an appropriate level of expertise to confirm that it is of an acceptable scientific standard.

The benefits of publishing with F1000Research:

- Your article is published within days, with no editorial bias

- You can publish traditional articles, null/negative results, case reports, data notes and more

- The peer review process is transparent and collaborative

- Your article is indexed in PubMed after passing peer review

- Dedicated customer support at every stage

For pre-submission enquiries, contact research@f1000.com 